\title{
Erratum to: Pro Angular
}

\section{Adam Freeman}

\section{Erratum to: \\ Pro Angular, \\ DOI 10.1007/978-1-4842-2307-9}

The published version of this book included spacing errors in code listings throughout the book. These code listings have been corrected and text has been updated throughout the book. The errors were not present in the downloadable source code.

The online version of the original book can be found under DOI 10.1007/978-1-4842-2307-9

Adam Freeman, Pro Angular

DOI 10.1007/978-1-4842-2307-9_30

Copyright (C) 2017 by Adam Freeman

Adam Freeman

30, Woodley Headland

MK6 3PA, Milton Keynes, Bucks

UK

e-mail: adam.freeman.uk@gmail.com 